\section{Patents and indigenous lore}

SIR - Commenting on the controversy about patenting products from the neem tree (Nature 377,$89 ; 1995$ ) you gave the opinion that while we cannot dismiss the claim of unfair discrimination against indigenous knowledge, the patents should be judged on (their genuine originality and) the terms on which they were granted, not the extent to which they conflict with traditional knowledge systems that have only a marginal role in the modern world (my emphasis). The trouble is that today's patenting system permits companies and individuals to lay claims to techniques based on the indigenous knowledge of developing countries, if they are able to extend this knowledge using modern methods; in other words, a veneer of modernism over traditional 'prior art'. Traditional knowledge systems play more than a marginal role in the modern world; indeed, they form the basis of the 'drug hunting' in which companies and inventors are involved, whether in Costa Rica or Southern Asia. How did W. R. Grace come to know of the properties of neem?

To that extent, patenting extraction procedures or products from sources that were well-known, albeit through empirical or traditional wisdom, would amount to 'folk wisdom piracy', because it turns public good into a private commodity. The coalition of 200 Green groups that is petitioning against the W. R. GraceUSDA patent urges us not to forget that such cormmercial interest in the neem tree will lead to large-scale purchase of neem seeds at US\$300 per tonne, essentially pricing these seeds beyond the reach of local farmers and forcing them to rely on the modern formulated product rather than traditional recipes.

\section{Balasubramanian}

Centre for Cellular \& Molecular Biology, Hyderabad 500 007, India

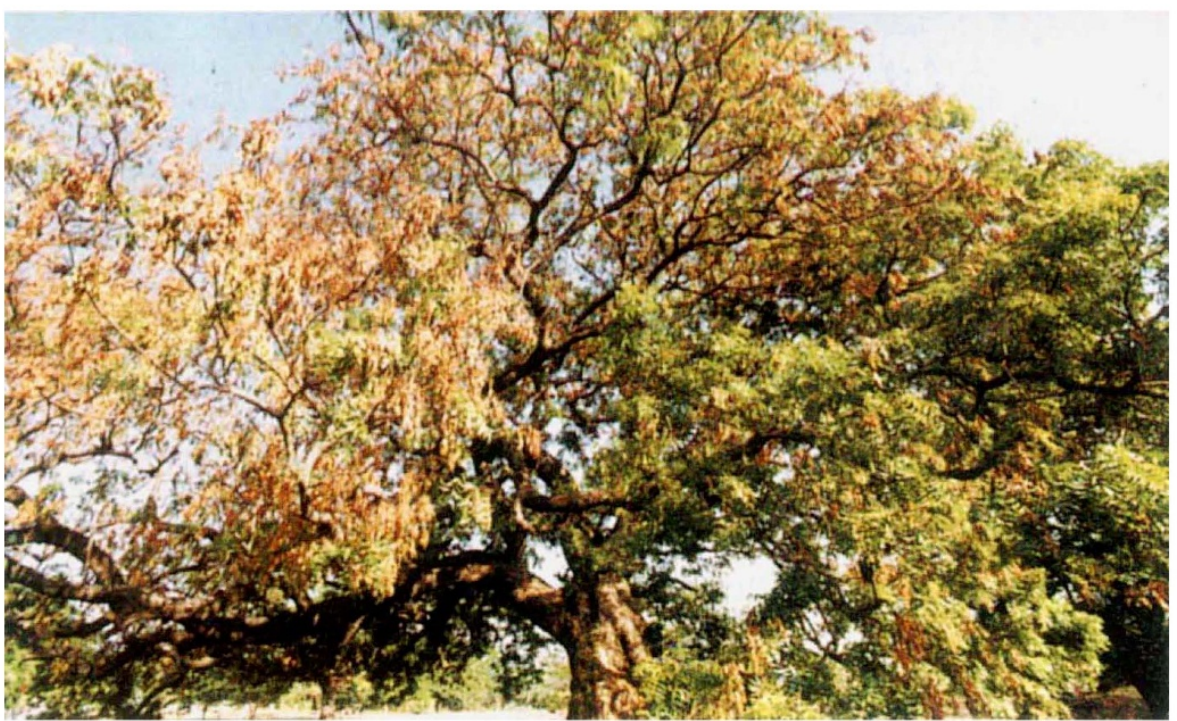

SIR - India's remarkable neem tree grows wild wherever it is allowed to in the area in which $\mathrm{I}$ live $\left(13.04^{\circ}\right.$ north of the Equator). Indian women have for centuries placed sprays of the neem among stored clothes to deter insect pests, and the neem's insecticidal properties have always been widely recognized.

Perhaps what is less known is its purported medicinal value. When smallpox was still rampant, poultices of neem leaves were used to relieve the unbearable burning of the lesions. Indian villagers may be excused for believing that the neem will also alleviate other clinical conditions. Thus at two villages, one not far north of Madras, an annual fair is held when pilgrims first bathe and then parade around a small shrine dedicated to Mariamma, believed to be the goddess of smallpox, wearing nothing but small garments of neem leaves. Far from vanishing with the disappearance of smallpox, this annual festival has been gaining in popularity over the years and is an amazing spectacle.

But if the neem is so efficient an insecticide, why is the tree itself so prone to a devastating insect attack almost every year? Just before the very hot weather begins in this part of India, all our neem trees are attacked by an insect, with the result that the end leaves of the trees turn a dirty brown and fall off (see photograph)

One year this infestation was so bad that owners of affected neem trees were preparing to cut them down in the belief that the trees had died. But the trees recovered as they always do.

The Chief Conservator of Forests of the State of Tamil told me that the insect responsible is the 'tea mosquito', which does also attack tea as well as cashew and other plants. No one, however, seems to know the taxonomic name of this parasite or any other details about it.

The mystery, therefore, is why a tree renowned for its insecticidal properties is itself so vulnerable to the attacks of an insect.

\section{Harrry Miller}

3A Satyanarayana Avenue,

Boat Club Road,

Madras,

India 600028

\section{Anticancer drugs}

SiR - Petsko ${ }^{1}$ (rightly) congratulates Takahara and colleagues for obtaining the high-resolution crystal structure of the cisplatin-DNA adduct ${ }^{2}$. He also suggests that related heavy-metal compounds may have antitumour properties, and that such complexes may be "attractive candidates for rational design projects". But is the pursuit of new anticancer drugs that nonspecifically damage DNA worth large expenditures of time and money?

Despite the introduction of numerous chemotherapeutic agents, cancer survival rates for clinically advanced tumours have improved little in the past 30 years. With the exception of testicular cancer and a few other rare neoplasms, solid malignancies when disseminated remain incurable, and treatment can only be palliative. Failure of treatment with chemotherapy is due generally to de novo intrinsic resistance of subpopulations of tumour cells to anticancer drugs, and, after several cycles of therapy, resistant clones predominate in the tumour cell population ${ }^{3}$. Thus the physician encounters the common clinical scenario in which a cancer initially regresses after chemotherapy, followed by lack of tumour response to further drug treatment and, invariably, progression of the disease. It is unlikely that new agents (with similar mechanisms of action) will circumvent such resistance.

Clinical and molecular oncologists must acknowledge that nonspecific cytotoxic chemotherapy drugs will never be effective in the treatment of the common solid cancers. The continued development of these agents will result at best in marginal improvements in survival and quality of life, and will require the use of enormous resources. Such resources would be better used further to define the molecular alterations that cause cells to become malignant, and to design therapeutics that target those alterations.

David M. Reese

Division of Hematology/Oncology, UCLA School of Medicine,

Los Angeles,

California 90095, USA

1. Petsko, G.A. Nature 377, 580-581 (1995)

2. Takahara, P. et al Nature 377, 649-652 (1995)

3. Gottesman, M. M. \& Pastan, I. Trends pharmac. Sci. 9 , 54 (1988).

An old neem tree in Madras after attack by the 'tea mosquito'. 